\title{
Analytical, Experimental and Numerical Methods to Quantify the Pres- surization on the Piston Chamber of Axial Piston Machines*
}

\author{
Markus GÄRTNER ${ }^{* *}$, Filipp KRATSCHUN** and Hubertus MURRENHOFF**
}

\begin{abstract}
In mobile and stationary applications, axial piston machines are often used as pumps or motors. The paper on hand deals with the pressurization behavior of swash plate axial piston units. The pressurization is influenced amongst others by the pressure on high and low pressure line $p_{\mathrm{HP}}$ and $p_{\mathrm{LP}}$ and the rotational speed $\omega$, geometric properties, e.g. the dead volume

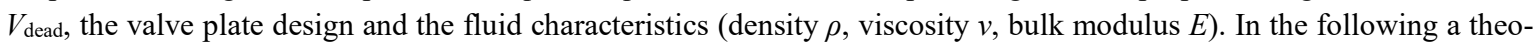
retical and an experimental analysis of the pressurization in the piston chamber and the resulting compression work is presented.
\end{abstract}

Keywords: axial piston machine, pressurization, bulk modulus, compression work

\section{Introduction}

In the past many researchers focused their work on the dynamic behavior, flow respectively pressure ripples and the acoustic emission of axial piston machines. Fiebig ${ }^{1)}$ made a holistic analysis of noise generation of hydraulic aggregates. Pumps are indicated as main noise source which is influenced by the commutation between high and low pressure and pressure pulsation. Schleihs et. al. ${ }^{2)}$ coupled pressure measurements in a cylinder block of a swash plate machine and a CFD analysis using the so-called Equilibrium Dissolve Gas Model to localize cavitation critical areas and to suggest a design optimization.

This paper deals with a detailed view on the effects that influence the pressurization in the piston chamber respecting the losses in the system consisting of piston chamber, valve and the connected piping. As a consequence of the complex resistance of the liquid column and the dissipated compression work a pressure loss and vibrations occur.

The presented work is divided into three parts. In the first part a single piston test rig from the IFAS laboratory is described. This test rig was built up for experimental research of the tribological behavior of the piston-bushing contact in swash plate machines ${ }^{3)}$. Amongst other measured variables the dynamic pressure in the piston chamber was recorded.

\footnotetext{
* Manuscript received January 15, 2018

** Institute for Fluid Power Drives and Controls (IFAS)

RWTH Aachen University

Campus Boulevard 30, 52074 Aachen, Germany

E-mail: markus.gaertner@ifas.rwth-aachen.de
}

With a view to a more precise understanding and an optimization of the commutation, a 1D-simulation model of the single piston test rig was built up. Based on the test results the simulation is validated.

The third part deals with a theoretical study concerning the fluid characteristics and its effect on the compression work. The compression work is calculated respecting the relative amount of entrained air. For the theoretical study the pump and suction processes are compared to an ideal process cycle.

\section{Nomenclature}

\begin{tabular}{lll}
$E$ & $:$ & Bulk modulus \\
$m$ & $:$ & Material constant \\
$n$ & $:$ & Polytropic exponent \\
$p$ & $:$ & Pressure \\
$x$ & $:$ & Piston stroke \\
$V$ & $:$ & Volume \\
$W$ & $:$ & Work \\
$\alpha$ & $:$ & Amount of entrained air \\
$\varphi$ & $:$ & Rotation angle \\
$\kappa$ & $:$ & Specific heat ratio \\
$\rho$ & $:$ & Density \\
$\omega$ & $:$ & Rotational speed \\
$v$ & $:$ & Kinematic viscosity \\
Subscript & & \\
0 & $:$ & Start value \\
air & $:$ & Air \\
$\mathrm{C}$ & $:$ & Compression \\
dead & $:$ & Dead \\
diss & $:$ & Dissipated \\
& & \\
\hline & &
\end{tabular}




$\begin{array}{lll}\text { dyn } & : & \text { Dynamic } \\ \text { init } & : & \text { initial } \\ \text { E } & : & \text { Expansion } \\ \text { eff } & : & \text { Effective } \\ \text { HP } & : & \text { High pressure } \\ \text { LP } & : & \text { Low pressure } \\ \text { norm } & : & \text { normalized } \\ \text { oil } & : & \text { Oil } \\ \text { opt } & : & \text { Optimal } \\ \Delta \mathrm{C} & : & \text { Loss }\end{array}$

\section{Experimental Investigation}

At the Institute for Fluid Power Drives and Controls (IFAS), RWTH Aachen University, the tribological behavior of the piston-bushing contact of axial piston units in swash plate design is investigated mainly with experimental work, secondarily with simulation work, in the recent past ${ }^{4)-5}$. While analyzing the test results like friction work, piston rotation, etc. the pressurization in the piston chamber must be kept in mind.

\subsection{Single Piston Test Rig}

The measurement presented here is executed on a single piston test rig in the IFAS laboratory. This test rig was built up to analyze the radial and tangential friction work, leakage and temperature distribution in the piston-bushing contact. An overview of the test rig is given in fig. 1 .

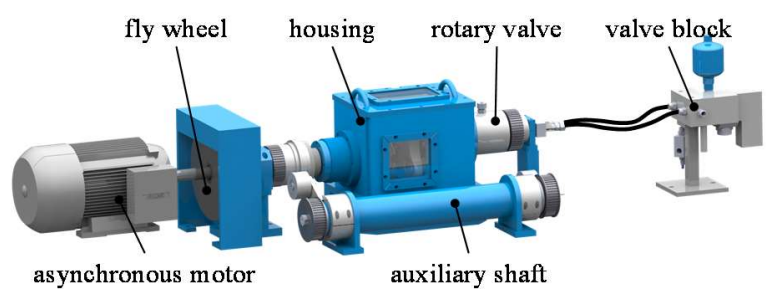

Fig.1 Overview of the single piston test rig

This test rig consists of a central structure, located in the housing (see fig. 2), which guides the piston via a bushing mounted in a force measurement plate. The force measurement plate is fixed to the housing with four piezo load cells. Via the compensation piston, the piston chamber is connected to the rotary valve outlet without causing a force shunt. A wobble plate, driven by an asynchronous motor, generates the piston stroke. Due to the hold down device a piston slipper lift off is prevented.

The piston chamber pressure, called $p_{\text {dyn }}$ in the following, is captured with a piezo-electric pressure transducer situated in the swivel plate.

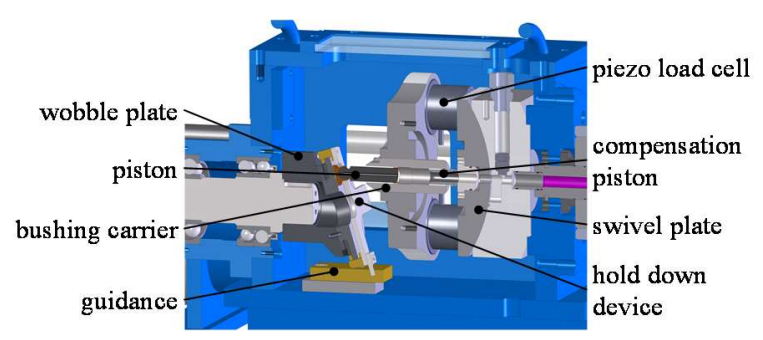

Fig.2 Sectional view of the guiding unit

Figure 3 depicts the rotary valve that connects the piston chamber with the high or low pressure level ( $\left.p_{\mathrm{HP}} ; p_{\mathrm{LP}}\right)$, which is controlled with pressure control valves at the valve block. The rotary valve is synchronized with the wobble plate via an auxiliary shaft.

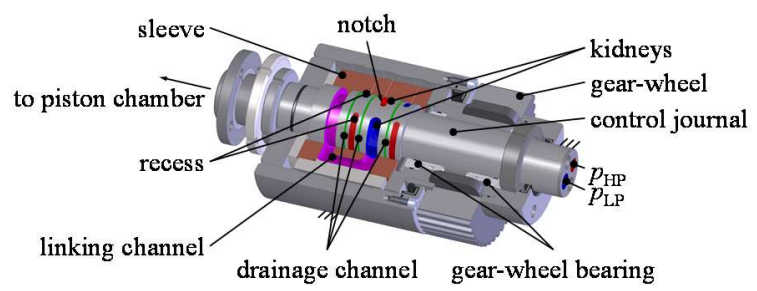

Fig. 3 Sectional view of the rotary valve

A linking channel is machined into the sleeve, which is located on the fixed control journal and driven by a gear wheel. With the rotating linking channel in the sleeve, the valve outlet is connected with the high or low pressure line ( $\left.p_{\mathrm{HP}}, p_{\mathrm{LP}}\right)$.

Regarding fig. 1 and 2, the dead volume $V_{\text {dead }}$ of the entire pressurized chamber consists of the piston chamber and the valve outlet and is therefore much larger compared to commercial swash plate pumps on market. This leads to a delayed pressurization and a higher amount of compression work. Therefore, the pressurization can be studied easily.

\subsection{Test Results}

The measurements are carried out at a speed of $\omega=500 \ldots 2750 \mathrm{rpm}$ and a pressure $p_{\mathrm{HP}}$ between 10 and $35 \mathrm{MPa}$. In fig. 4 , left the measured chamber pressure $p_{\text {dyn }}$ is plotted across a full piston stroke at different rotational speeds. The high pressure level is held at $30 \mathrm{MPa}$ and the low pressure level is adjusted to $5 \mathrm{MPa}$ to lower the risk of cavitation.
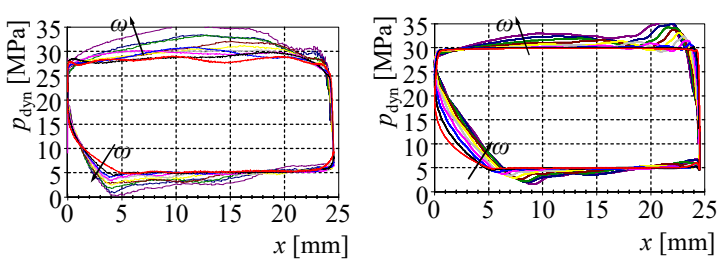

Fig.4 Measured and simulated pressurization 
The measured pressure levels during suction and pump stroke differ from the set pressures $p_{\text {LP }}$ and $p_{\text {HP. The commu- }}$ tation from low to high pressure is faster, caused by an early valve opening relative to the large capacity between piston and valve outlet. When the piston has its maximum speed at a stroke between 10 and $15 \mathrm{~mm}$, a pressure increase during the pump stroke is visible. The same behavior can be seen vice versa during the suction stroke. This effect becomes more noticeable with increasing rotational speed $\omega$. It is caused by the total hydraulic resistance, the inductivity and the capacity of the liquid column in the piping between piston chamber and valve block outlet. The total hydraulic resistance is the sum of all hydraulic resistors such as pipes, elbows and control edges in the valve.

Two effects can be seen while commutating from high to low pressure. The pressure in the suction stroke tends to drop to zero as another consequence of the hydraulic resistance. Hence, the need to pressurize the low pressure line up to $5 \mathrm{MPa}$ becomes clear. Furthermore, the pressure decrease is slower than it was expected using analytical calculations (compare fig. 7). This behavior is affected by leakage in the rotary valve that flows from the high pressure kidney to the low pressure kidney. When the linking channel is connected to the low pressure kidney, this volume flow induces such an altered pressure decrease.

\section{Simulation}

To get a more precise understanding of the pressurization in the piston chamber, a 1D-simulation model was built up. This model considers the frequency dependent friction according to Theissen ${ }^{6}$ ) and does not consider heat transfer. The operating parameters of the shown experiment (fig. 4) and the simulation are the same. Figure 4, right depicts the simulation results.

The model was parametrized appropriate to the geometric dependencies of the single piston test rig described above. From an abstract point of view, this model is a network of elements such as hydraulic resistors like pipes, elbows, gaps, cross section changes etc. In pipes and gaps the flow regime is supposed to be laminar. The sharp-edged resistors are assumed to behave like orifices (turbulent flow assumed). A deformation of valve parts caused by pressure fields and external forces is considered by a pressure dependent gap flow. Thermal effects like thermal strain or a temperature distribution in the valve are not implemented just as complex flow conditions e.g. turbulence or cavitation effects.
The difference between experimental and simulation results are small. Hence the simulation model is validated by measured data. The simulation model can be used for several tests that would not be possible with experiments or would take much more time.

The valve timing was varied using the simulation model. So the already used adjustment of the rotary valve at the test rig is confirmed. Furthermore, an optimization of design features is possible.

\section{Theoretical Study}

The following theoretical study is aimed towards finding an analytical solution that quantifies the pressurization in the piston chamber and the compression losses of axial piston machines. In particular, the influence of the fluid's compressibility and the valve timing on the pressurization within the piston chamber are regarded and compared to an ideal reference cycle.

\subsection{Reference Cycle}

The ideal reference cycle of a hydraulic swash plate machine is shown in fig. 5 below.

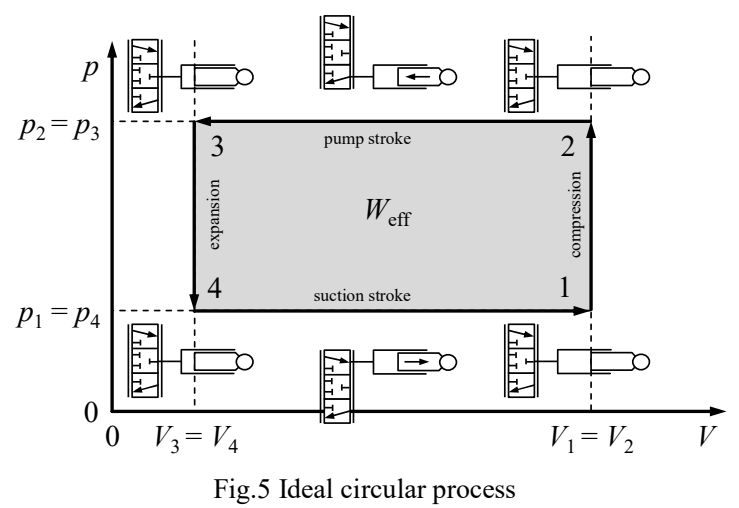

The valves' positions represent the relative position of the valve plate to the piston chamber. At the beginning of the cycle (1) the cylinder is completely filled with the working fluid and the piston chamber is about to be disconnected from the low pressure port. Between (1) and (2) the pressurization takes place which means that the piston chamber is disconnected from both ports and the piston pressurizes the enclosed fluid. Having reached point 2 the high pressure port is connected to the piston chamber and the piston pushes the fluid out of the cylinder until it reaches the inner dead center (3). This represents the pump stroke wherein the effective work $W_{\text {eff }}$ is being released. Then the cylinder is being disconnected from the high pressure port and is being connected to the low pressure 
port (4) which induces a pressure drop within the piston chamber. Once connected with the low pressure port, the piston chamber is being filled with the working fluid until it is completely full and the cycle restarts from (1) again.

In a real machine, there are three main deviations from the ideal cycle. Firstly, the fluid is elastic, which results in additional compression work which has to be applied to pressurize the fluid. Secondly, the valve opening and closing process is of finite velocity. Thirdly there are friction and flow losses within the cylinder, which were examined in the previous chapter. The following chapter deals with losses due to the compressibility of the fluid.

\subsection{Compression Losses}

As mentioned before the fluid is rather elastic. Entrained air in the shape of micro bubbles reduces the stiffness (bulk modulus) of the fluid significantly, which is shown in this chapter. In literature, there are several models known for the calculation of the effective bulk modulus of hydraulic fluid with entrained air. Gholizadeh et. al. ${ }^{7)}$ summarized selected fluid models concerning the fluid bulk modulus disregarding the effect of entrained air, which is feasible at a high pressure. In ${ }^{8)}$, the effect of air in hydraulic cylinders on the eigenfrequency and the stiffness of the hydraulic system at pressures under $10 \mathrm{MPa}$ are studied by analytic and experimental work. Kajaste ${ }^{9)}$, Kim ${ }^{10)}$ and Ruan ${ }^{11)}$ analyzed several models and examined experimental validations under different temperatures and different amounts of entrained air. According to Findeisen ${ }^{12)}$ dissolved air has no effect on the physical characteristics of hydraulic oil. In the given paper, the IFAS ${ }^{13)}$ approach is taken to calculate compression losses. Herein the fluid volume is regarded as a perfect composition of air volume and oil volume, as shown in (1).

$$
V=V_{\text {air }}+V_{\text {oil }}
$$

The bulk modulus for pure hydraulic oil without entrained air depends on the pressure $\mathrm{p}$ as follows in (2) ${ }^{13)}$. Herein $E_{0}$ is the bulk modulus of pure oil at atmospheric pressure and $\mathrm{m}$ is a fluid specific material constant that needs to be identified by measurements. In this paper, these values are set to $E_{0}=1500 \mathrm{MPa}$ and $m=10$ (see gray continuous line in fig. 7).

$$
E_{\text {oil }}=E_{0}+m \cdot p
$$

The bulk modulus of the entrained air is derived from the polytropic approach (9). Furthermore, the relative amount of entrained air $\alpha$ is introduced and is defined by (3).

$$
\alpha=\frac{V_{\text {air }}}{V}
$$

The composed bulk modulus (IFAS model) can be derived using the equations mentioned above and is given by (4), considering the linear pressure dependency in equation 3 and the relative amount of entrained air $\alpha$, the atmospheric pressure $p_{0}$, the current pressure $\mathrm{p}$ and a material constant $\mathrm{m}$. Kim verified this model with measurements ${ }^{10)}$.

$$
E_{\text {oil +air }}=\frac{(1-\alpha) \cdot\left(1+\frac{m \cdot p}{E_{0}}\right)^{-\frac{1}{m}}+\alpha\left(\frac{p_{0}}{p}\right)^{\frac{1}{\kappa}}}{\frac{1}{E_{0}}(1-\alpha) \cdot\left(1+\frac{m \cdot p}{E_{0}}\right)^{-\frac{m+1}{m}}+\frac{\alpha}{\kappa \cdot p_{0}}\left(\frac{p_{0}}{p}\right)^{\frac{\kappa+1}{\kappa}}}
$$

Figure 6 shows the bulk modulus of the IFAS model compared to the models of Nykänen, Wiley and Yu, wherein the bulk modulus of the pure oil is considered to be constant ${ }^{9), 11)}$ The influence of entrained air is obvious and cannot be neglected within the derivation of the compression work.

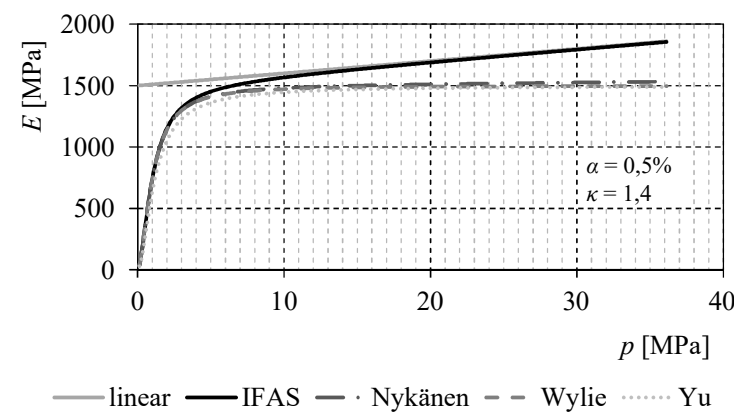

Fig.6 Bulk modulus across pressure $p$ according to different fluid models

The elasticity of the fluid has to be implemented into the reference cycle, which can be seen in the figure below.

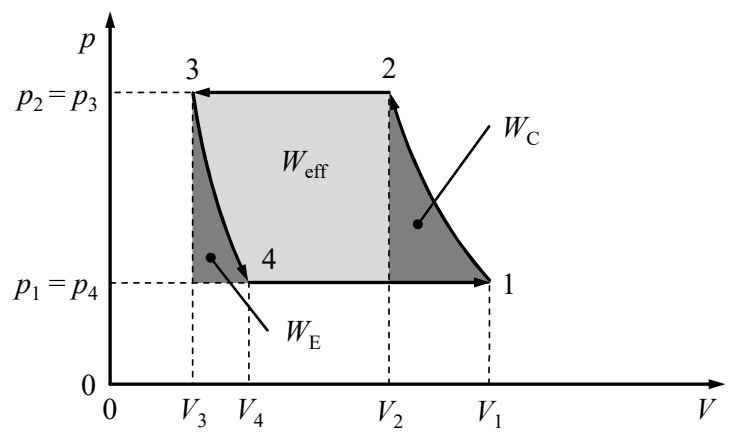

Fig.7 Calculation of the compression work

Herein $W_{\mathrm{C}}$ is the compression work needed to pressurize the fluid. $W_{\mathrm{E}}$ is the expansion work, which is done by the fluid, once the low pressure port is connected to the pressure chamber. Since the stroke volume was exerted by the pump, only the dead volume (V3) remains under high pressure and therefore the expansion work done by the remaining volume has to 
be less than the compression work, which had to be added to the pump. The difference of the compression work and the expansion work is defined as compression loss, since that amount of energy has to be added to the pump's shaft.

The compression and expansion work can be calculated by solving equation 5 , which holds true for both, oil and entrained air within the chamber volume. Therefore, a function $p(V)$ is needed for both phases.

$$
W_{12}=\int_{1}^{2} p d V
$$

For the oil phase equation (6), proposed by Murrenhoff ${ }^{13)}$, is taken and inverted, which leads to equation (7). Integrating equation 7 leads to the compression work needed for the pressurization of the oil within the piston chamber.

$$
\begin{aligned}
& V(p)=(1-\alpha) V_{1}\left(1+\frac{m p}{E_{0}}\right)^{-\frac{1}{m}} \\
& p(V)=\frac{E_{0}}{m}\left(\left(\frac{V}{V_{1}}\right)^{-m}-1\right)^{-\frac{1}{m}} \\
& W_{\mathrm{C}, \text { oil }}=\frac{V_{1} E_{0}}{m}\left[\frac{1}{1-m}\left(\frac{V}{V_{1}}\right)^{1-m}-\frac{V}{V_{1}}\right]_{V_{1}}^{V_{2}}
\end{aligned}
$$

For the air phase, the polytropic approach (9) is chosen, wherein $n$ is the polytropic exponent. For an isentropic process, $n$ is set to the specific heat ratio of air $\kappa=1.4$ and for an isothermal process $n$ is set to unity. The integration of $p$ over $V$ leads to equation (10) for the isentropic case and (11) for the isothermal case.

$$
\begin{aligned}
& p(V)=p_{1}\left(\frac{V}{V_{1}}\right)^{-n} \\
& W_{\mathrm{C}, \text { air }}=\frac{\alpha V_{1} p_{1}}{1-n}\left[\left(\frac{V}{V_{1}}\right)^{1-n}\right]_{V_{1}}^{V_{2}} \\
& W_{\mathrm{C}, \text { air }}=\alpha V_{1} p_{1} \ln \left(\frac{V_{1}}{V_{2}}\right)
\end{aligned}
$$

Since the equations for the compression work of both phases are derived, the pressurization work of the entire fluid can be calculated. It is assumed that the compression of the entrained air takes place isentropically, but the thermal diffusion of the compressed entrained air leads to an immediate pressure loss within the bubbles. This leads to energy dissipation of the compressed air, whose amount is the difference of the isentropic and isothermal process, which is derived by the subtraction of (10) and (11) and inserting (9) resulting in (12).

$$
W_{\text {C,air,diss }}=\alpha V_{1} p_{1}\left(\left(\left(\frac{p_{2}}{p_{1}}\right)^{\frac{\kappa-1}{\kappa}}-1\right) \frac{1}{\kappa-1}-\ln \left(\frac{p_{2}}{p_{1}}\right)\right)
$$

The derivation of the equations for the expansion work is done the same way it is carried out for the compression work and leads to (13) and (14).

$$
\begin{aligned}
& W_{\mathrm{E}, \text { oil }}=\frac{V_{3} E_{0}}{m}\left[\frac{1}{1-m}\left(\frac{V}{V_{3}}\right)^{1-m}-\frac{V}{V_{3}}\right]_{V_{3}}^{V_{4}} \\
& W_{\mathrm{E}, \text { air }}=\frac{\alpha V_{3} p_{3}}{1-n}\left[\left(\frac{V}{V_{3}}\right)^{1-n}\right]_{V_{3}}^{V_{4}}
\end{aligned}
$$

Finally the compression loss can be calculated by adding the compression and expansion work which results in (15).

$$
W_{\Delta \mathrm{C}}=W_{\mathrm{C}, \text { iil }}+W_{\mathrm{C}, \text { air,diss }}+W_{\mathrm{E}, \text { iil }}+W_{\mathrm{E}, \text { air }}
$$

Figure 8 (left), depicts the normalized dissipated compres-

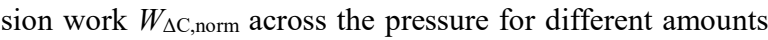
of entrained air. The center graph shows a detail of the left diagram at low pressure.

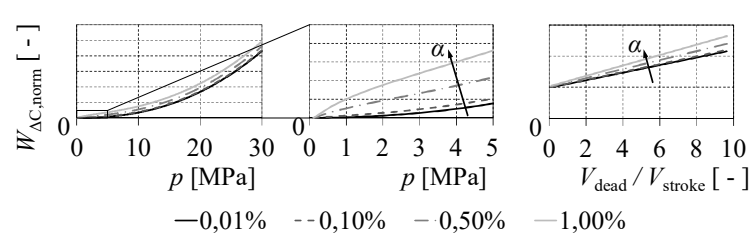

Fig.8 Normalized dissipated compression work over pressure $p$ and dead volume $V_{\text {dead }}$ for different entrained air values

In fig. 8 (right), the influence of the dead volume is plotted. It can clearly be seen that dissipation due to the compression is unavoidable by reducing the dead volume.

Compared to the losses caused by friction in the piston bushing contact, the dissipated compression work has the same order of magnitude in a wide operation range. The friction work in this contact has a very complex behavior and depends amongst others on the rotational speed of the hydraulic unit. Because of its complexity a more detailed analysis relating to the friction work is not part of this paper.

\subsection{Ideal Valve Timing}

The operating point that is characterized by the pressure level at the high and low pressure port, the rotational speed, the swash plate angle, the fluid temperature, the amount of entrained air and also the design of the pump (e.g. dead volume) influence the pressurization in the piston chamber. To achieve an efficient and low noise operating of the axial piston unit the valve timing needs to be adapted. For an ideal valve timing $\varphi_{\text {opt }}$ the valve opens when the piston chamber pressure 
has reached the set pressure level $p_{\mathrm{HP}}$ or $p_{\mathrm{LP}}$ (point 2 or 4 in fig. 7). Most commutation devices in swash plate pumps are designed for a certain operational area. These non-adaptive devices show following effects when the valve opens too late (fig. 9 a) or too soon (fig. 9 c).

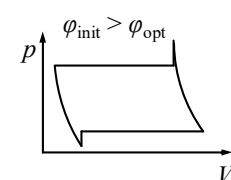

(a)

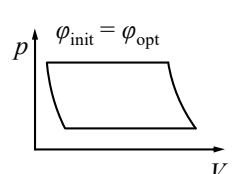

(b)

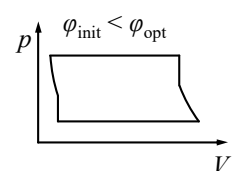

(c)
Fig.9 Over- and under-compression in the piston chamber due to dif-

$$
\text { ferent valve timing (c.f. }{ }^{14)} \text { ) }
$$

These effects are explained by means of the compression process. The expansion can be regarded analogously. A too late valve opening induces a pressure peak in the piston chamber followed by a short equalizing volume out-flow of the piston chamber. This not only leads to pressure pulsation and noise emission but also to a drive torque peak. When the valve opens too early, the pressure in the piston chamber needs to be adapted by a volume flow into the chamber, that is, contrary to the usual flow direction. As a consequence the effective volume flow of the pump is reduced.

\section{Conclusion}

Via an experimental investigation on a single piston test rig, a 1D-Simulation and an analytic study the pressurization of the piston chamber is examined.

First measurements of the piston chamber pressure are presented and analyzed. Afterwards a 1D-simulation model is built up according to the dimensional properties of the single test rig. This simulation is validated with the measured data. Both analyses show similar results. Finally the compression losses are calculated and related to the friction losses. The calculations revealed that the compression losses lie within the same range as the friction losses and therefore cannot be neglected, which contradicts the common theory. Afterwards the effect of unfitted valve timing on the operating behavior of axial piston units is discussed. By means of experimental data and a 1D-simulation model the main effects on the pressurization in the piston chamber are analyzed. Mostly the complex resistance of the valve and the effective bulk modulus have an effect on the operating behavior regarding the efficiency and noise emission. A determination of the ideal valve timing can only be done respecting these characteristics.

\section{References}

1) Fiebig, W.: Schwingungs- und Geräuschverhalten der Verdrängerpumpen und hydraulischen Systeme Vorgehensweise, Maßnahmen und Potential zur Geräuschminderung, Berichte aus dem Institut für Werkzeugmaschinen, Tübingen (2001)

2) Schleihs, C. et al.: 3D-CFD simulation of an axial piston displacement unit, 9th International Fluid Power Conference, Aachen (2014)

3) Vatheuer, N.: Untersuchung des Bewegungsverhaltens schräggestellter Kolben in Schwenkscheibenmaschinen, Dissertation, Aachen (2016)

4) Gels, S.: Einsatz konturierter und beschichteter KolbenBuchse-Paare in Axialkolbenmaschinen in Schrägscheibenbauweise, Dissertation, Aachen (2011)

5) Gärtner, M. et al.: Comparison of analytical and experimental investigation of volumetric losses in the pistonbushing contact of axial piston machines, Antriebstechnisches Kolloquium, p. 107-115 (2017)

6) Theissen, H.: Die Berücksichtigung instationärer Rohrströmung bei der Simulation hydraulischer Anlagen, Dissertation, Aachen (1983)

7) Gholizadeh, H. et al.: Fluid Bulk Modulus: A Literature Survey, International Journal of Fluid Power, vol.12,No.3, p. 5-15 (2011)

8) Gholizadeh, H. et al.: Fluid Bulk Modulus: Comparison of low pressure models, International Journal of Fluid Power, Vol.13,No.1, p. 7-16 (2012)

9) Kajaste, J. et al.: Experimental Validation of Different Models for Effective Bulk Modulus of Hydraulic Fluid, 9th Scandinavian International Conference, Linköping (2005)

10) Kim, S.: Measurement of effective bulk modulus and its use in CFD-Simulation, Dissertation, Aachen (2012)

11） Ruan, J., Burton, R.: Bulk Modulus of Air Content Oil in a Hydraulic Cylinder, Proceedings of IMEC2006, ASME International Mechanical Engineering Congress and Exposition, Chicago, Illinois, USA (2006)

12) Findeisen, D.,Helduser, S.: Ölhydraulik, Springer, Berlin, Heidelberg (2015)

13) Murrenhoff, H., Fundamentals of Fluid Power - Part 1: Hydraulics, Lecture Notes, Aachen (2014)

14) Fister, W.: Fluidenergiemaschinen, Springer, Berlin (1984) 


\section{Appendix}

Table 1 Experimental parameters

\begin{tabular}{|c|c|c|}
\hline Parameter & Variable & Quantity \\
\hline Pressure [MPa] & $p_{\mathrm{HP}}$ & $10 \ldots 35$ \\
\hline & $p_{\mathrm{LP}}$ & 5 \\
\hline Speed [rpm] & $\omega$ & $500 \ldots 2750$ \\
\hline Fluid temperature $\left[{ }^{\circ} \mathrm{C}\right]$ & $\vartheta$ & 40 \\
\hline Wobble plate angle $\left[{ }^{\circ}\right]$ & $\beta$ & $0 \ldots 20$ \\
\hline Approx. piston diameter $[\mathrm{mm}]$ & $d$ & 20 \\
\hline Approx. piston length $[\mathrm{mm}]$ & $l$ & 70 \\
\hline
\end{tabular}

Table 2 Utilized sensors

\begin{tabular}{|c|c|c|}
\hline Measurand & Manufacturer & Classification \\
\hline Speed & Heidenhain & ROD 426/5000 \\
\hline Pressure sensor & Kistler & 4075 A500 \\
\hline Load cells & Kistler & 9366BB \\
\hline Temperature & Sensorpro & KTY \\
\hline
\end{tabular}

